\title{
Moving infrastructure benefits beyond projects and programmes
}

\author{
Recent research confirms the growing limitation of infrastructure projects and programmes to deliver \\ long-term benefits to society. A more holistic, system-level approach to infrastructure delivery and \\ management is needed, say Carron Blom and Peter Guthrie from the University of Cambridge.
}

Notwithstanding calls to make better use of existing infrastructure, the project-centric, linear-life-cycle view of infrastructure delivery and management has little changed. This is despite a move towards managing work programmes rather than individual projects, and using a portfolio approach to asset management.

Others argue that infrastructure governance has also failed to evolve, that life-cycle feedback is absent and that application of theory to the practice of aligning strategy and operations is largely unexplored (Busby, 1998; Dobbs et al., 2013: p. 4; Flyvbjerg et al., 2003; Johnston and Pongatichat, 2008)

Six years ago, former Institution of Civil Engineers president Paul Jowitt observed that a more holistic and inclusive approach to infrastructure was required. He said it was the time to reorient civil engineering practice back towards its imperative: that of delivering societal benefits (Jowitt, 2010).

\section{A global problem}

Recent research carried out by the Centre for Sustainable Development at the University of Cambridge found that, despite a growing awareness within infrastructure practitioners of the need for a holistic approach, there are still widespread issues in fully delivering appropriate and relevant infrastructure outcomes over the long term (Blom and Guthrie, 2016).

The research, across a number of countries and infrastructure sectors, found that this cannot simply be explained away as poor organisational, sector or country performance. It suggests a different approach is required better to understand and then deliver long-term infrastructure benefits.

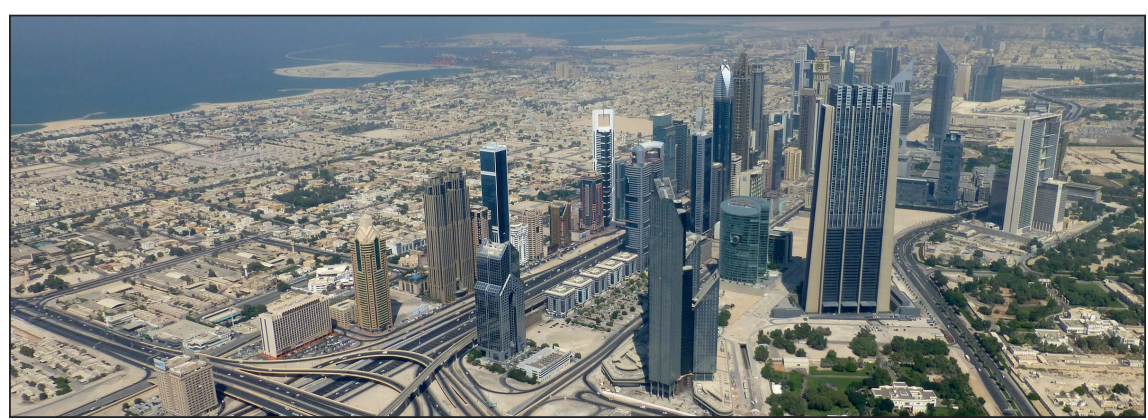

All infrastructure needs to be seen in the context of a system servicing society rather than individual projects

What also emerged was that systemlevel benefits are rarely being followed through to integrating projects into their operational infrastructure systems - comprising assets, other projects and networks. In other words, while project success may have been evaluated in terms of conventional project management success factors, systemlevel feedback is largely absent.

\section{Managing reality}

The conventional asset life cycle - of plan, build, maintain and dispose presumes the building of more projects and then the optimisation of those hard assets. This may have been appropriate in the establishment of 'new world' economies or in response to specific events such as postworld-war or disaster recovery.

But the 'pipeline' view of infrastructure does not help manage the complexities of less-tangible objectives and the messy, non-linear reality of day-to-day service-led infrastructure management. It is also no longer appropriate to think of benefits in terms of engineering-led conventions rather than customer-oriented outcomes (Blom and Guthrie, 2015; Blom et al., 2015).
There is clearly an urgent need to move beyond individual projects and programmes and to consider systemlevel benefits - not through the current project- or programme-oriented view but rather from the perspective of the system itself and the benefits it seeks to achieve.

\section{References}

Blom C and Guthrie P (2015) Surveying customer perceptions of road infrastructure comfort. Infrastructure Asset Management 2(4): 173-185.

Blom C and Guthrie P (2016) Towards long term infrastructure systems performance. Proceedings of the Institution of Civil Engineers - Engineering Sustainability, http://dx.doi.org/10.1680/ jensu.15.00035.

Blom C, De Marco L and Guthrie P (2015) Customer perceptions of road infrastructure surface conditions. Infrastructure Asset Management 2(1): 23 -38.

Busby J (1998) The neglect of feedback in engineering design organisations. Design Studies 19(1): 103-117.

Dobbs R, Pohl H, Lin DY et al. (2013) Infrastructure Productivity: How to Save \$1 Trillion a Year. McKinsey Global Institute, London, UK.

Flyvbjerg B, Skamris Holm M and Buhl S (2003) How common and how large are cost overruns in transport infrastructure projects? Transport Reviews 23(1): 71-88.

Johnston R and Pongatichat P (2008) Managing the tension between performance measurement and strategy: coping strategies. International Journal of Operations \& Production Management 28(10): 941-967.

Jowitt $P$ (2010) Now is the time. Proceedings of the Institution of Civil Engineers - Civil Engineering 163(1): 3-8, http://dx.doi.org/10.1680/cien.2010.163.1.3. 